\title{
Primary Central Chondrosarcoma
}

National Cancer Institute

\section{Source}

National Cancer Institute. Primary Central Chondrosarcoma. NCI Thesaurus. Code C7155.

A chondrosarcoma arising from the central portion of bone without a benign precursor. 